Giasemi Vavoula and Stamatina Anastopoulou

\title{
School Visits Post-lockdown: \\ The Role of Digital \\ A Survey Report
}

this is something which we would need to consider anyway as school visits are compromised by school budget cuts
Whilst digital has a place in helping us share with schools from a distance I strongly believe it cannot replace ... inperson visits
Building digital resources will also extend our reach in the longer term we need to invest more time and money into making it good and worthwhile
I think now we've tried a lot of things, we'll end up seeing what is popular, what works, and what we can do within our capabilities there are great opportunities to broaden access to our museum through ... digital approaches
At the moment we don't have the budget
I like digital experiences when they are thought provoking and allow students to try their hands at things they would not be allowed to do in our museum
The challenge will be developing a financial model that works
Pre and post visit virtual activities in the classroom could better support teachers and pupils to make the most out of in person visits. 
UNIVERSITY OF
LEICESTER

ISBN: 978-1-912989-10-2

DOI: https://doi.org/10.29311/2020.69

Copyright (C) 2020 Giasemi Vavoula and Stamatina Anastopoulou
This work is licensed under the Creative Commons Attribution 4.0 International License. To view a copy of this license, visit http://creativecommons.org/licenses/by/4.0/ or send a letter to Creative Commons, PO Box 1866, Mountain View, CA 94042, USA. 


\section{Contents}

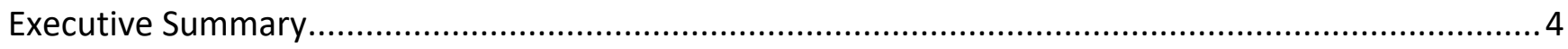

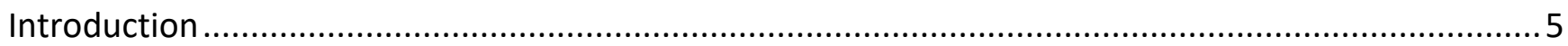

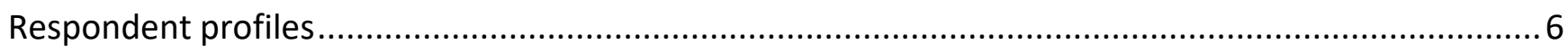

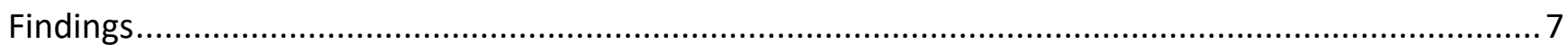

Section A. 'Your museum's pre-covid19 school visit offer' ....................................................... 7

Section B. 'Your museum's post-lockdown school visit plans' ..................................................10

Section C. 'Digital activities and school visits post-lockdown' ..................................................16

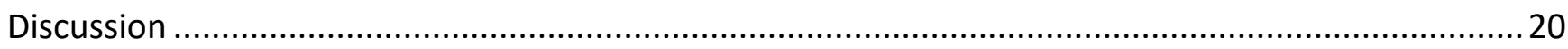

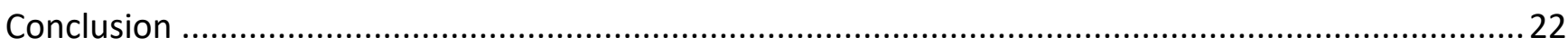

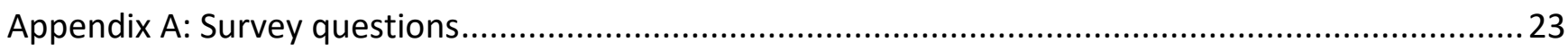




\section{Executive Summary}

We report findings from the survey "School Visits Post-Lockdown" by the School of Museum Studies, University of Leicester. We surveyed museum educators and other museum professionals who are involved in the planning and/or delivery of school visits. The survey aimed to understand the new contexts in which schools and museums are called to continue their educational synergies, the challenges that these contexts present, and the potential uses of digital technologies and tools in responding to these challenges. The survey remained open between 27 May and 20 June 2020 and received 76 complete responses. The main findings are:

- The main challenges facing museum school services post-lockdown are: uncertainty over new rules and regulations; pandemic impacts on museum, school and family budgets; and staff and public confidence in new health \& safety procedures and practices.

- The modifications in response to these challenges that are mostly under consideration are: increasing the use of digital activities, increasing school outreach, and 'covid-proofing' on-site visits.

- Museum response planning is impacted by limited staff capacity and uncertainty over rules.

- Activities that require physical interactions (hands-on, interactive exhibits, etc.) are less favoured for post-lockdown school visits. In contrast, digital activities are $\sim 60 \%$ more likely to feature in post-lockdown visits than pre-covid.

- There is increased appetite for digital components in post-lockdown school visits. On average, we can expect 3 additional digital components post-lockdown than we had pre-covid. More likely to be added are home activities, virtual tours, live lectures, online collections, bitesize talks, and social media.

- Nearly all participants (95\%) said that there will/may be a future for blended (face-to-face and digital) school visits. The most favoured way of blending digital components into school visits was through pre- and post-visit engagement. The most frequently identified benefit was the expansion of the museum's reach beyond its usual catchment area. The most mentioned drawbacks were development costs and the loss of physical interactions and engagement.

- A period of intensification of the integration of digital activities within school visits may be imminent; a period that presents unique opportunities to explore how museum pedagogies can guide the planning of flexible, blended school visits that combine face-to-face and online activities. In this, the museum learning sector will need support and coordinated efforts. 


\section{Introduction}

In the months before the covid19 pandemic, we were working on a project ${ }^{1}$ that sought to apply inquiry learning pedagogies to school visits to science centres. We had been examining research and empirical evidence of what students and teachers do on these visits, and we were developing Rapid Inquiry as a school visit pedagogy that builds curiosity and reflection into the interactive, multisensory play that dominates science centre experiences. We were also looking to develop a digital tool to support Rapid Inquiries. The lockdowns that were subsequently imposed across the world saw the cancelation of hundreds of school visits while schools and museums were bounced into digital engagement. What could Rapid Inquiry and other school visit pedagogies offer in this new context? In a world that seemed to have gone digital overnight, what tools and technologies could help keep schools and museums meaningfully connected during and after the lockdown? What lessons can we take from such digital experimentations into our longer-term design and planning of school visits? In order to better understand the parameters of these questions and the new contexts in which schools and museums are called to continue their educational synergies, we surveyed museum educators and other museum professionals who are involved in the planning and/or delivery of school visits.

The survey was designed and administered electronically via the JISC Online Surveys platform. Information about the survey and calls for participants were disseminated via social media and the Group for Education in Museums (GEM) discussion list. The survey remained open between 27 May 2020 and 20 June 2020. It comprised 21 questions in total, of which 11 were open, four were Likertscale questions, and six were single choice questions. These focused on the likely disruptions, challenges and changes in school visits as a result of covid19 and covered three main thematic sections ('Pre-covid19 school visit offer'; 'Post-lockdown school visit plans'; and 'Digital activities and school visits post-lockdown'), with one additional section related to participants' profiles. The survey included a cover page which explained the purposes and outlined the focus of the questions and asked for participant consent. A copy of the survey can be found in Appendix A.

We received 78 responses, of which 76 were complete. The following sections present data and findings from the analysis of these responses. More specifically, section 2 contextualises the data through an analysis of respondent profiles. Section 3 presents data and findings from the three main sections of the survey. Section 4 concludes the report with a summary of findings and outlines our plans for future research in this area.

\footnotetext{
${ }^{1}$ For more on the Science-MINQ project see https://cordis.europa.eu/project/id/792600
} 


\section{Respondent profiles}

We asked respondents to describe their museum roles; these related to education, learning, public engagement, community / youth programming, and lifelong learning. The most frequently used role qualifiers were 'manager' and 'officer' (31\% each), followed by 'assistant' and 'educator' ( $5 \%$ each) and 'head' and 'leader' (4\% each). Other qualifiers included facilitator, team member, freelancer, director, trustee, producer, curator, and teacher, while $3 \%$ of the respondents said they were the only person responsible for learning in the museum.

In order to gauge the respondents' involvement in the planning and delivery of school visits and other public engagement activities, we asked how often ('regularly', 'occasionally', or 'never') their role requires them to undertake tasks/responsibilities related to these. Sixty two percent $(62 \%)$ of the respondents are regularly involved in the planning and/or delivery of both school visits and other public engagement activities; $21 \%$ are regularly involved in the planning and/or delivery of school visits but only occasionally or never in other public engagement; $11 \%$ are regularly involved in public engagement but only occasionally or never in school visits; $5 \%$ are occasionally involved in the planning/delivery of both; and only $1 \%$ said they are only occasionally involved in the delivery of other public engagement only.

We also asked respondents about their current employment situation, in order to contextualise responses related to current thinking within their museum during the lockdown. Of the 76 respondents who answered this question, $78 \%$ said that they were working from home at the time they completed the survey; $3 \%$ were working on-site; $5 \%$ split their time between home and on-site working; $1 \%$ had been redeployed to another unit; $1 \%$ were self-employed; and $12 \%$ were furloughed. 


\section{Findings}

\section{Section A. 'Your museum's pre-covid19 school visit offer'}

\section{"1. In your opinion, how important are school visits to your museum?"}

Seventy five (75) respondents answered this question. There was overall agreement among respondents regarding the importance of school visits, with $73 \%$ of participants indicating that school visits are very important to their museum, $23 \%$ indicating that school visits are important, and $4 \%$ indicating that school visits are moderately important.

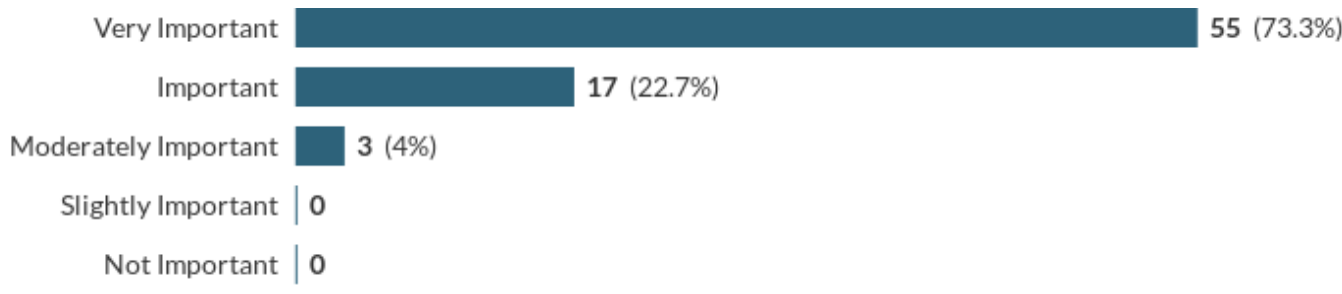

Figure 1. How important are school visits to your museum?

\section{"1a. In your opinion, what makes school visits important for your museum?"}

Seventy four (74) respondents answered this question. The majority of responses (62\%) linked school visits to the mission of the museum, either by naming educational activities as part of the core mission or by highlighting the educational benefits of museum visits for school pupils. Almost a third of responses (32\%) highlighted the importance of the income that comes from school visits. Several responses mentioned that school visits contribute directly to increasing visitor numbers (16\%) and to audience development (28\%) through creating links with teachers as well as students and their families. Engagement with local communities and the potential to link education with local heritage and history were also mentioned.

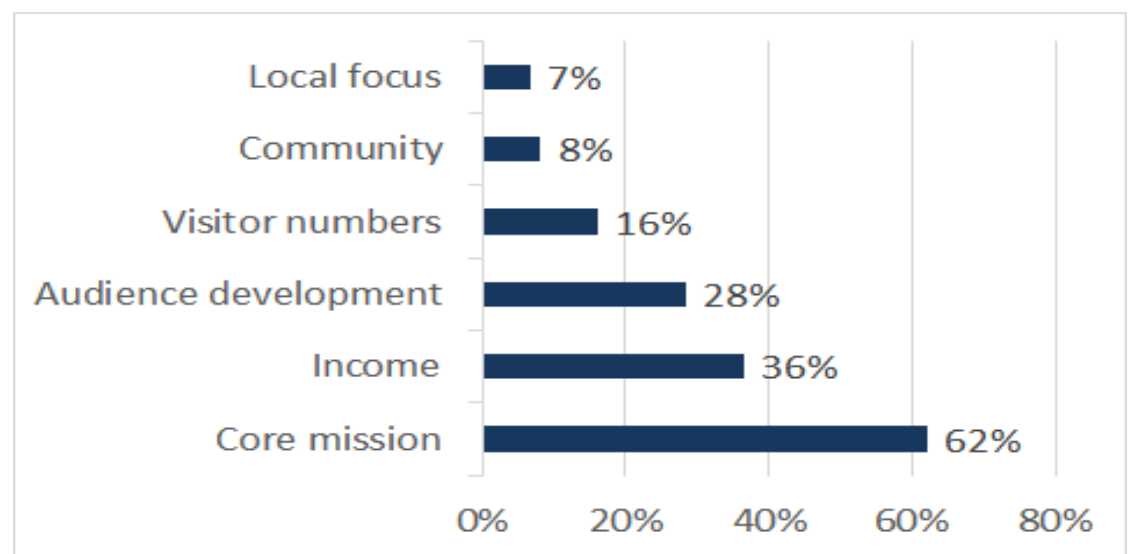

Figure 2. What makes school visits important for your museum: coding of free text responses. Note that a single response may have been coded into more than one category depending on content. 


\section{"2. Which of the following types of activity did your museum's pre-covid19 school visit offer include?"}

Seventy six (76) respondents answered this question. Hand-on activities, trails and teacher-guided student investigations were included by more than three quarters of respondents, with hands-on activities being a nearly universal feature of school visits pre-lockdown. Over half of the respondents said that their school visits included playing with interactive exhibits, self-guided student investigations, gallery tours, demonstrations or lectures, and critical thinking activities. Digital activities featured in just over $40 \%$ of the responses, while under one third included games. One quarter of the respondents said that other activities were also included in their school visit plans, including workshops (mentioned by 15 ) and costumed-based activities (mentioned by 3 ). Responses to this question paint a picture of school visits where students are active, hands-on, and guided to explore the museum, its contents and concepts.

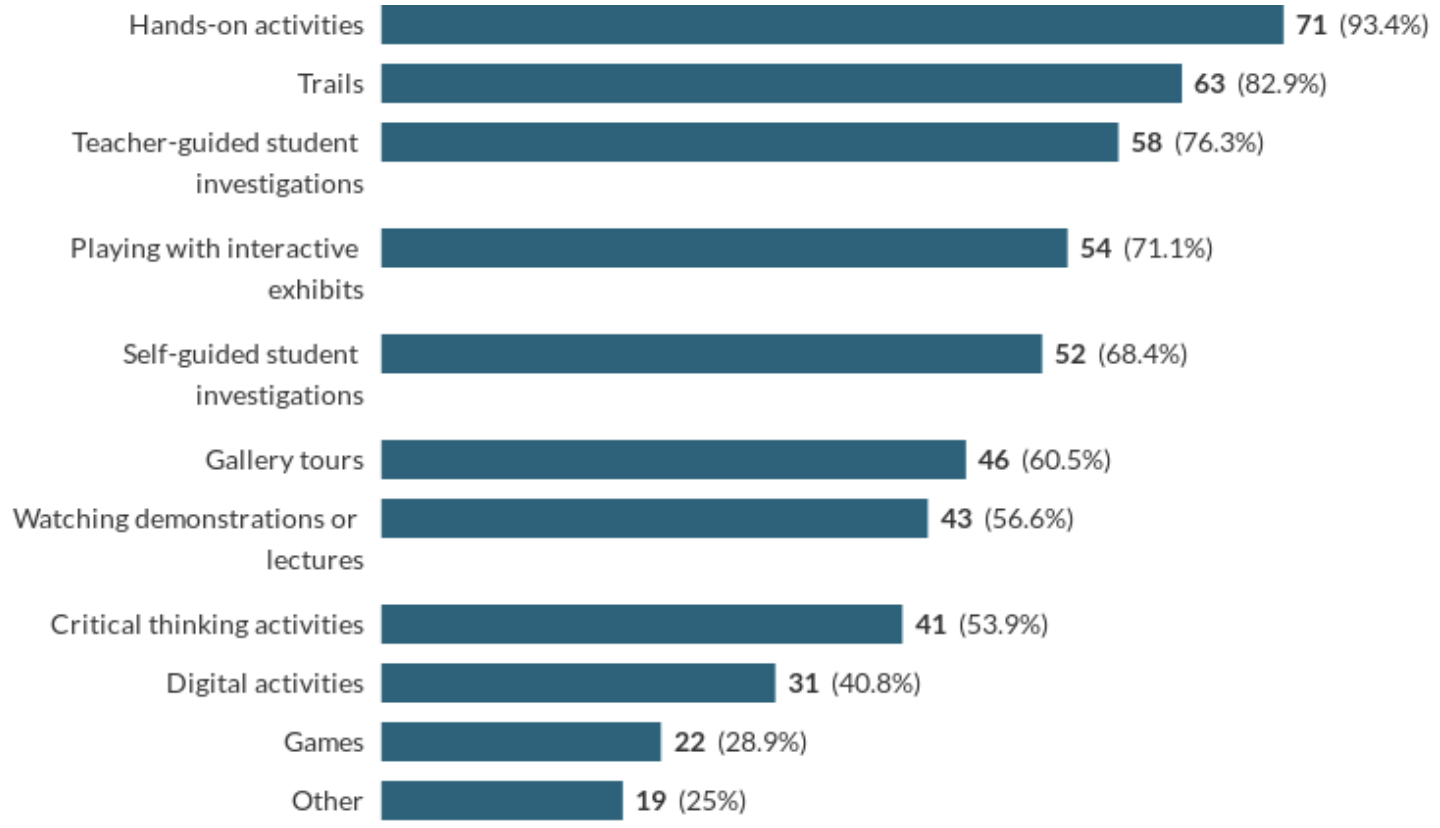

Figure 3. Types of activities included in pre-covid19 school visit offer.

\section{"3. If your museum's pre-covid19 school visit offer included digital activities, which of the following were used?"}

There were 73 responses to this question. Just under one third of the respondents said that their museum's school offer did not include digital activities. Over half of the respondents said that their museum offers teacher resources, just under one third said that their museum uses social media, just over one quarter said that their museum offers online collections, and just over one fifth offer virtual tours ( 22\%). Less common appear to be online games and mobile apps (both at $15 \%$ ), home activities ( 14\%), and bitesize talks and live lectures (both at $\sim 4 \%$ ). Finally, one respondent said that their museum's school visit offer includes Lego education apps. 


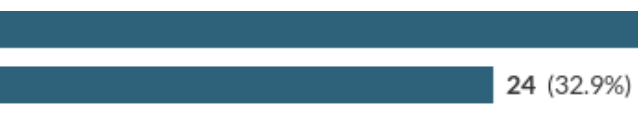

activities
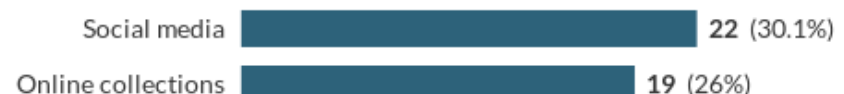

Online collections

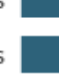

$19(26 \%)$

Mobile apps

$16(21.9 \%)$

Online games

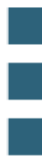

Home activities

Live lectures

Bitesize talks

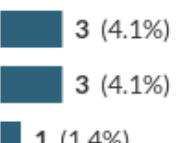

Other $1(1.4 \%)$

Figure 4. Types of digital activities included in school visit offer pre-covid19.

While only 31 respondents had said that their school visit offer includes digital activities in the previous question, only 24 respondents said explicitly in this question that their school visit does not offer digital activities and 41 said that they do offer (digital) teacher resources. This discrepancy may indicate varying perceptions of what a digital offer includes; for example, online downloadable lesson plans and other teacher resources may not be seen by everyone as distinctly "digital" activities. It may also indicate varying understandings of what is part of the school visit offer, for example teacher resources that are meant to be used in the classroom or in pre-visit preparations may not be seen as part of the school visit.

Nevertheless, the results clearly indicate that a considerable proportion of museums were already using various digital technologies and media to support school visits before the pandemic. 


\section{Section B. 'Your museum's post-lockdown school visit plans'}

\section{“4. To your knowledge, is your museum considering offering a school visit service post-lockdown?”}

There were 76 responses to this question. The vast majority of respondents ( $\sim 4 \%$ ) answered yes with only $5 \%$ giving a negative answer and just over $10 \%$ unsure.

\section{"5. To your knowledge, has your museum been able to keep relationships with schools going during the lockdown?"}

There were 76 responses to this question. Just over half of the respondents ( $51 \%)$ said that their museum had been able to keep in contact with schools during the lockdown, just under one third ( $32 \%)$ said the museum had not been able to do so, and $\sim 17 \%$ were not sure.

Respondents who answered 'yes' to this question were also asked, "How has your museum done this?"

The responses gave details about who the museum kept in contact with and what media they used to do so. More specifically, one third of the respondents who had answered yes to the previous question mentioned contact with teachers and another third mentioned contact with schools more generally. Four respondents mentioned home learning or families. Email was the most frequently mentioned means of communication (one third of respondents), followed by newsletters and social media (one quarter and one fifth of respondents respectively). Website updates and phone calls were mentioned by $10 \%$ of respondents each.

In addition, one third of the respondents also talked about what they offer in these communications, including online content (6), learning resources (6), activities (1), online CPD (1) and curriculum advice (1).

Overall, it appears that at least half of the museums have kept in touch with schools and teachers, primarily through email, newsletters and social media. This is in line with the perceptions outlined in earlier questions regarding school visits being at the core of the museum's mission, and shows willingness to support school learning and keep nurturing relationships with school communities during the lockdown.

"6. What issues or challenges do you anticipate your museum will face in resuming its school visits service post-lockdown?"

The main challenges facing museum school services post-lockdown are uncertainty over new rules and regulations; impacted museum, school and family budgets; and staff and public confidence in new health \& safety procedures and practices.
There were 76 responses to this question. The respondents mentioned challenges that related to how both museums and schools will adapt to the post-lockdown realities.

The most frequently mentioned challenges across museum and school settings related to the health, safety and wellbeing of staff, students and teachers

(over $72 \%$ of respondents mentioned these). Implementing social distancing properly is of particular concern because of the restrictions imposed by limited (and often small) museum spaces, and the time pressure of a school visit that may interfere with breaking classes down into smaller groups. Issues related to safeguarding staff were also mentioned, including potential need for PPE and how that might interfere with the delivery of sessions, and keeping staff safe on public transport for outreach activities. Sanitation of spaces, objects and interactive resources as well as shared facilities like toilets are also an 
issue for concern, as hygiene and deep cleaning requirements will likely interfere with session planning. The need to train staff in new social distancing and sanitation procedures was mentioned in this context, as was the option to reduce or eliminate hands-on activities. Additional concerns, particularly for museums with smaller spaces, relate to the co-presence in the galleries of school groups with other visitor groups, with some respondents considering exclusive school hours to mitigate the risks.

Other challenges mentioned related to the need to develop new types or forms of activities, including digital but also new outreach offers and adapting workshop/session formats. Of particular concern in undertaking these are anticipated reductions in budgets and staff capacity.

Regarding schools' adaptation to the post-lockdown reality, over one fifth of respondents expected that new school priorities will not include museum visits and over a third expected that schools (and parents) will take time to develop the confidence to take pupils on fieldtrips. Nearly $15 \%$ of respondents expected that financial issues will also hinder school visits, owing to reduced school budgets and/or parents' ability to afford school trip costs. Over one fifth of respondents anticipate that new school rules and requirements for social distancing and hygiene will hinder visits, and a similar proportion anticipate that transport, particularly public transport for local schools, will be an issue for similar issues.

Uncertainty over new social distancing and hygiene rules and regulations; impacted museum, school and family budgets; and staff and public confidence in new procedures and practices are the main challenges facing museum school services post-lockdown.

\section{"6a. How do you expect social distancing to impact school visits to your museum?"}

There were 75 responses to this question, elaborating further on the implications of implementing social distancing measures. The main concerns raised related to the health and safety issues that respondents mentioned in the previous question, i.e. the need for smaller school group sizes, the appropriateness of museum spaces, the implications for physical interactions, students' co-presence in galleries with other visitor groups, and use of shared facilities. A large proportion of respondents (40\%) discussed the implications of social distancing on the numbers of students that the museum can accommodate at a time. These implications were often discussed alongside space restrictions, which were of particular concern for smaller sites but also of concern to larger sites who make extensive use of smaller educational spaces. If for example a visiting year group has to be divided into smaller groups in order to adhere to social distancing restrictions, then more sessions will need to be delivered either in parallel (requiring more staff and space resources) or in succession (requiring shorter sessions to fit in the visit timeframe).

Responses indicate that social distancing requirements create additional pressures for smaller sites, from the lack of space to accommodate more than a handful of visitors at a time which renders educational visits impractical, to the need to timetable smaller groups and/or exclude other visitor groups during school visits. One other implication that was voiced by some respondents (but can also be inferred from many other responses) is that museums will be able to admit fewer schools overall because of social distancing requirements.

The intensification of school session delivery due to smaller group sizes combined with reduced overall visitor capacity due to social distancing may affect (severely, for some museums) the financial viability of school services. 
In relation to social distancing, respondents also discussed the need to (re)develop their school offer to include safe activities, for example by limiting (if not eliminating) handling sessions, activities that require physical interactions, and the handing out of resources (e.g. stationary). Concerns were also raised here regarding shared facilities including toilets, lunch and rest areas. The implications of social distancing requirements on transport to and from the museum were also mentioned in the responses to this question, particularly in terms of added costs for schools which might make school visits even less attractive. Finally, the anxiety, uncertainties and fear that might keep schools away were also acknowledged in the responses.

\section{"7. To your knowledge, are there plans to make any modifications post-lockdown to your museum's school visit offer? If yes, what modifications are being considered?"}

There were 73 responses to this question. The responses indicate that the modifications that are mostly under consideration relate to increasing the use of digital activities, increasing school outreach, and 'covid-proofing' on-site visits.

Over half of the modifications suggested related in some way to digital / online activities. Some respondents did not elaborate further and only referred generally to preparing a "digital offer", "online resources" or "distance learning"; others provided more detail, explaining that they are considering live events and talks (e.g. hot seating sessions, lectures, workshops, etc.), virtual tours, or video recordings. Three responses talked about a phased return to school visits, starting with online only options.

Outreach was seen as a potential alternative to on-site visits by almost $30 \%$ of participants. As with digital, some responses simply referred to 'outreach' while others elaborated more to explain for example how handling of objects and handouts would take place, what kinds of media would be used in the delivery of outreach sessions, and how loan boxes with objects and resources could safely be sent to schools.

Considerations regarding 'covid-proofing' of on-site visits were similar to those raised in the questions concerning social distancing and related health and safety issues post-lockdown. Responses mentioned: providing staff with PPE, accepting smaller student groups to maintain social distancing, securing exclusive access to the site for school groups, building in staff time and resources for sanitation of objects and spaces, 'quarantining' resources between visits, and reducing or outright banning the handling of objects/resources.

Combinations of these were also suggested, for example some outreach activities could be complemented by digital activities and followed by on-site visits at a later time.

Some respondents also mentioned challenges related to planning and implementing these modifications. Limited staff capacity, including due to furlough, was raised by $10 \%$ participants. Another challenge in planning for modifications was uncertainty over the rules for social distancing and the school requirements, with $\sim 15 \%$ of participants indicating that their museums were planning or undertaking consultations with schools and teachers. 


\section{"7a. Are there any other school visit modifications that you think your museum should consider? Please explain."}

There were 45 responses to this question, plus four respondents indicating that they were unsure. Of these, five suggested the introduction of 'online' or 'digital' elements; 11 responses suggested exclusive access to the facilities for schools during visits; and eight responses suggested sanitation measures (for hands, objects, interactives, etc.) Other suggestions referred to the implementation of social distancing (e.g. smaller student groups), the sanitation and safe use of shared facilities, and safe transport.

A few participants suggested in this question that post-lockdown planning should be looking at the longer term rather than short-term modifications only, with two suggesting for example that the situation presents an opportunity for their museum to rethink their approach to schools outreach in the longer term; another suggesting longer term rethink of object sanitation procedures; and two others suggesting a complete rethink of schools / education programmes.

\section{"8. How likely do you think it is that your museum's post-lockdown school visit offer will include the following types of activity?"}

This question aimed to compare intentions of using component activities in school visits in the postlockdown period with their actual use pre-covid. Figure 5 shows that most types of activity are likely to be included, with the exception of play with interactive exhibits, hands-on activities and games.

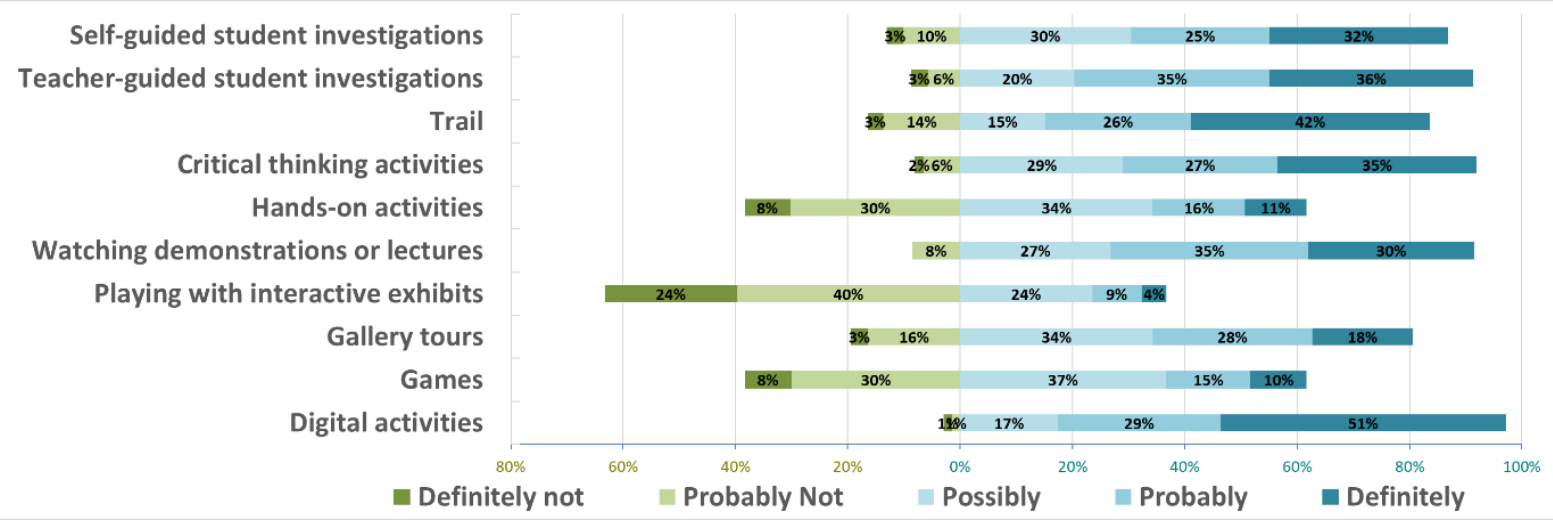

Figure 5. Likelihood of including different types of activities in post-lockdown school visit ("I do not know" responses are not shown in the graph).

Activities that require physical interactions

(hands-on, interactive exhibits, etc.) are less favoured for post-lockdown school visits. In contrast, digital activities are $\sim 60 \%$ more likely to feature in post-lockdown visits than pre-covid.
For comparison with pre-covid use, figure 6 below places these responses against responses to the earlier question, "2. Which of the following types of activity did your museum's pre-covid19 school visit offer include?" As one question asked participants to rate likelihood and the other asked them to confirm presence or absence, the two results are not directly comparable. However, in figure 5 we compare the 
percentages of 'positive likelihoods' (sum of 'possibly', 'probably' and 'definitely' percentages - light blue bar) against negative likelihoods (sum of 'probably not' and 'definitely not' percentages - olive green bar) on one hand; and against the percentage of confirmative answers in the pre-covid19 question (dark blue bar). As can be seen, the most sizable difference between pre-covid use and postlockdown intentions is in 'digital activities', which were included in just over $40 \%$ of pre-covid responses but received 'positive likelihood' answers by nearly $100 \%$ of respondents in the post-lockdown question. Similar changes can be seen in pre-covid19 and post-lockdown responses for critical thinking activities, watching demonstrations or lectures, and games; and to a lesser extent self- and teacherguided investigations, and gallery tours. In the opposite direction seem to be moving hands-on activities and playing with interactive exhibits, which are not seen as likely to be included in post-lockdown school visits as they were pre-covid. This is consistent with the issues raised by participants in relation to postlockdown health and safety, including social distancing and sanitation issues.

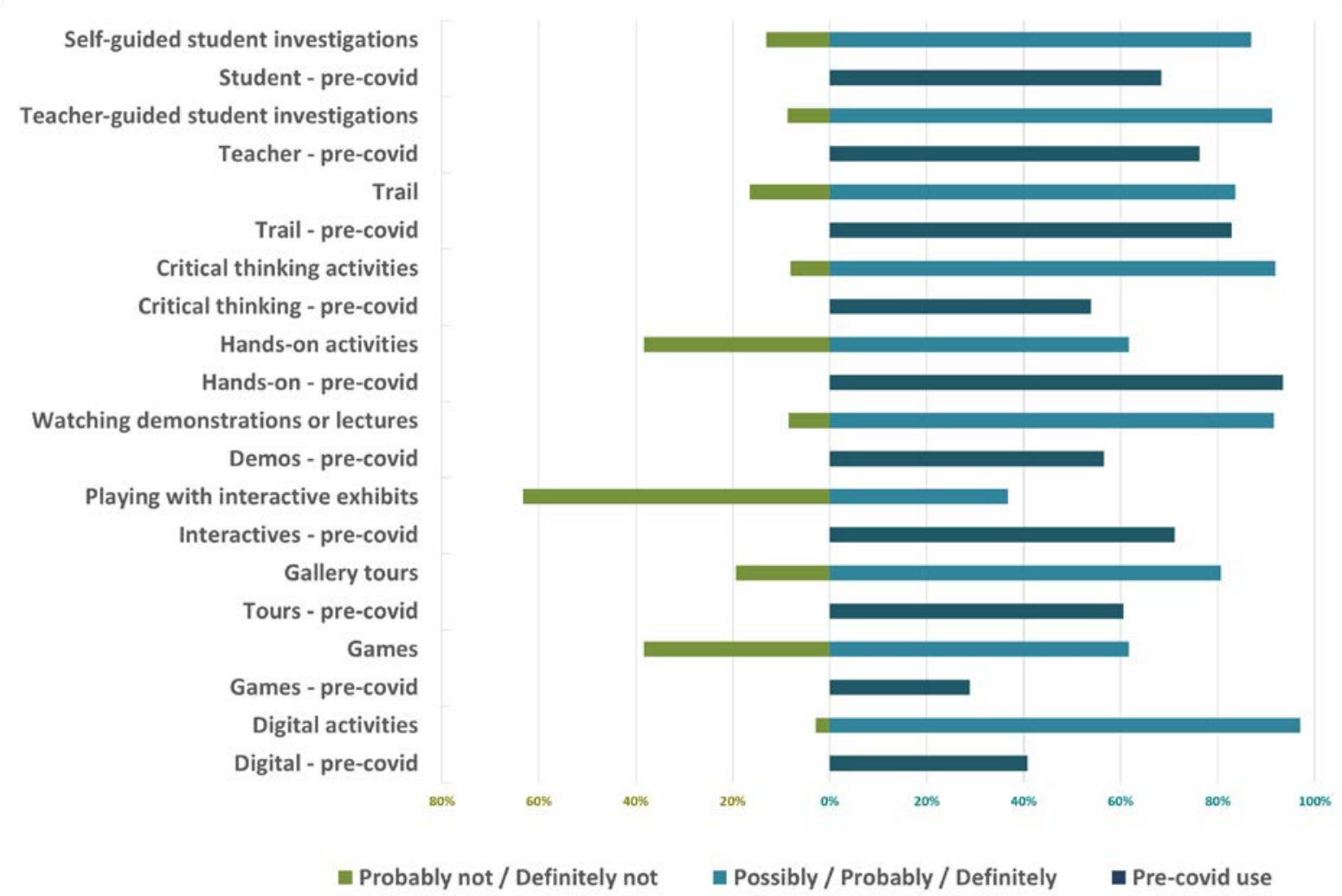

Figure 6. Likelihood of inclusion of different types of activities in post-lockdown school visits (olive green and light blue bars) versus inclusion in pre-covid19 school visits (dark blue bar).

\section{"8a. Are there any other types of activity that you think are likely to be included or should be included?"}

Different types of digital activities and events dominated the responses to this question, including offering online resources, digital tours and games, online sessions and virtual events, remote outreach, and coordinated cross-institutional online offers. Shifting from school visits to school outreach was also mentioned, as well as outdoor sessions and loans boxes. Acknowledging that lockdowns may return, some respondents suggested the inclusion of home activities, including for home-schooling. On-site activities mentioned included multisensory activities, costumed activities, performance, role play, workshops, and museum educator-led activities. Some respondents suggested self-led trails, small 
group activities and BYOD or Bring Your Own Kit, in the context of social distancing and covid19 hygiene. Finally, one respondent mentioned that they are considering hosting school classes in the museum (presumably to relieve social distancing pressures on local schools). 


\section{Section C. 'Digital activities and school visits post-lockdown'}

\section{"9. How important do you think digital activities will be in your museum's post-lockdown school offer?"}

The vast majority (67\%) of respondents anticipate digital activities to be 'very important' in their museum's post-lockdown school offer, and just under one third anticipate them to be 'important' or 'moderately important'. Only $4 \%$ of respondents said that digital activities will be only 'slightly important' or 'not important'. Given that only just over $40 \%$ of respondents had said that digital activities were included in their museum's pre-covid offer, clearly digital is gaining momentum in postlockdown school visit planning.

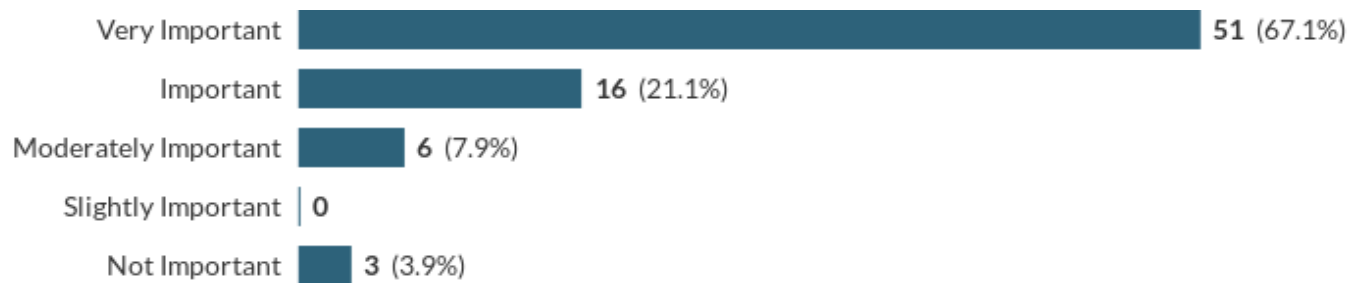

Figure 7. Importance of digital activities in post-lockdown school offer.

\section{"10. Which of the following do you think are likely to be used in digital activities of your museum's post-lockdown school visits?"}

This question had 75 responses. Figure 8 compares the percentage of responses that indicated that a component was likely to be included in post-lockdown digital activities, against the percentage of the same 75 respondents who had indicated in question 3 that the component was part of pre-covid digital activities. As can be seen in the graph, all components are significantly more likely to be included in postlockdown digital activities than they were used pre-

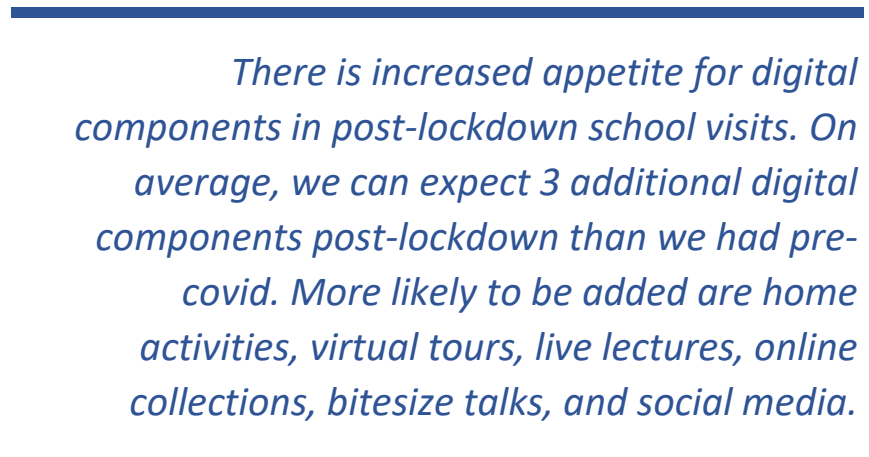
covid - with the exception of online games and mobile apps. The biggest differences between pre-covid and post-lockdown can be seen in home activities (nearly $70 \%$ more likely to be part of the post-lockdown digital offer), virtual tours and live lectures ( $\sim 50 \%$ more likely each), online collections and bitesize talks ( $\sim 5 \%$ and $\sim 40 \%$ respectively more likely), and social media ( 30\% more likely).

Significantly less enthusiasm appears to exist for online games and mobile apps post-lockdown. This may be due to perceived costs when many of the respondents anticipate reduced budgets; but may also relate to hygiene and general health and safety concerns and consequent reluctance to use potentially shared screens or devices. 


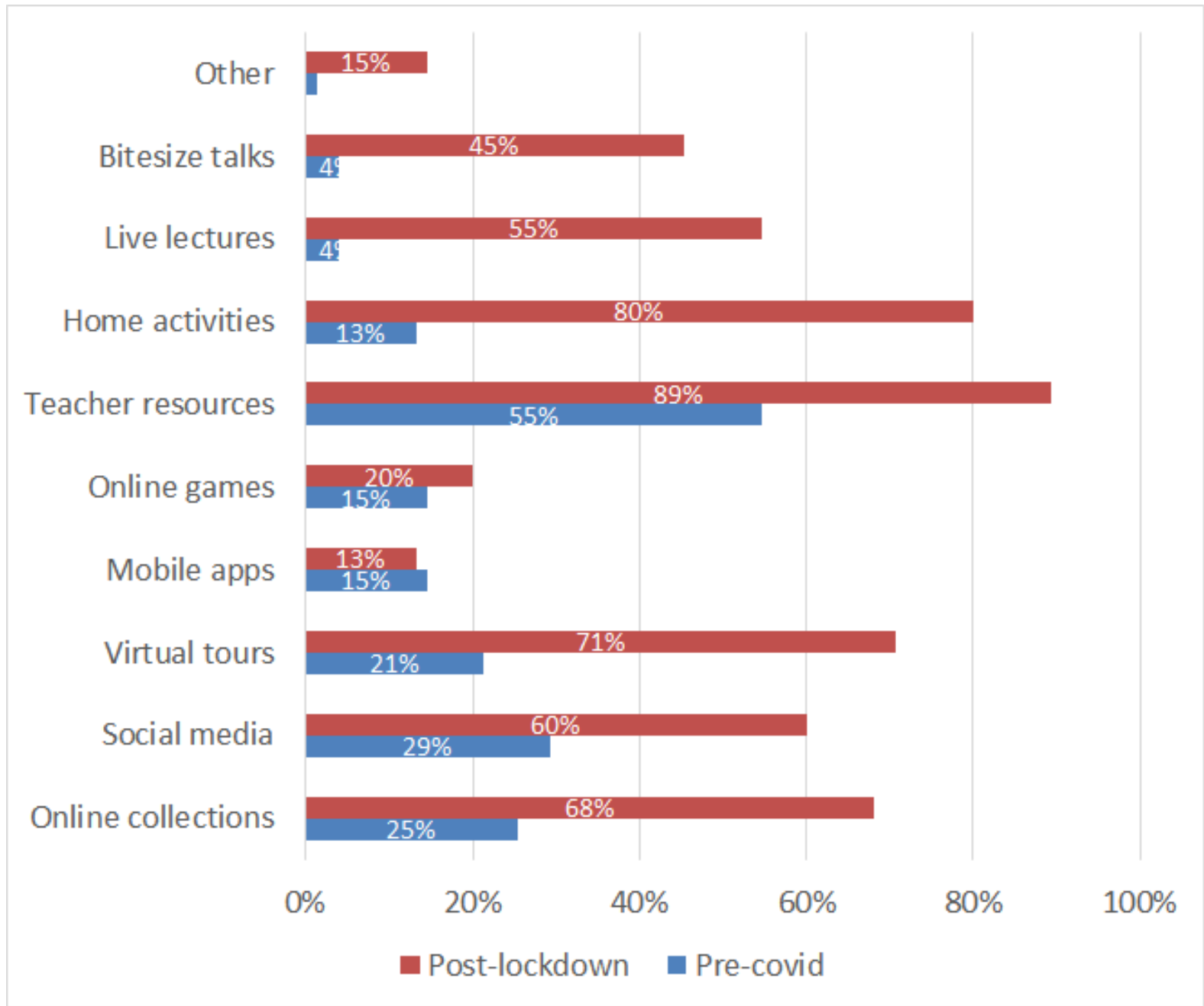

Figure 8. Components likely to be used in digital activities for school visits post-lockdown versus components used in digital activities pre-covid.

Other post-lockdown digital components mentioned by respondents included live interactive workshops, costumed/character sessions, hot seating sessions, topic/in-role videos, lessons, special events, and teacher training sessions. The need for high quality pre- and post-visit resources were also mentioned, to compensate for potentially shorter interactive sessions.

Overall, the responses to this question indicate increased appetite for digital components to be added to school visits post-lockdown. Figure 9 shows differences between the number of such components that a respondent said are likely to be included post-lockdown and the number that the respondent said were included pre-covid. As can be seen, only 9 participant responses (12\%) indicate that this difference will be zero (no change in number) or negative (fewer components post-lockdown than precovid). The median difference was +3 . 


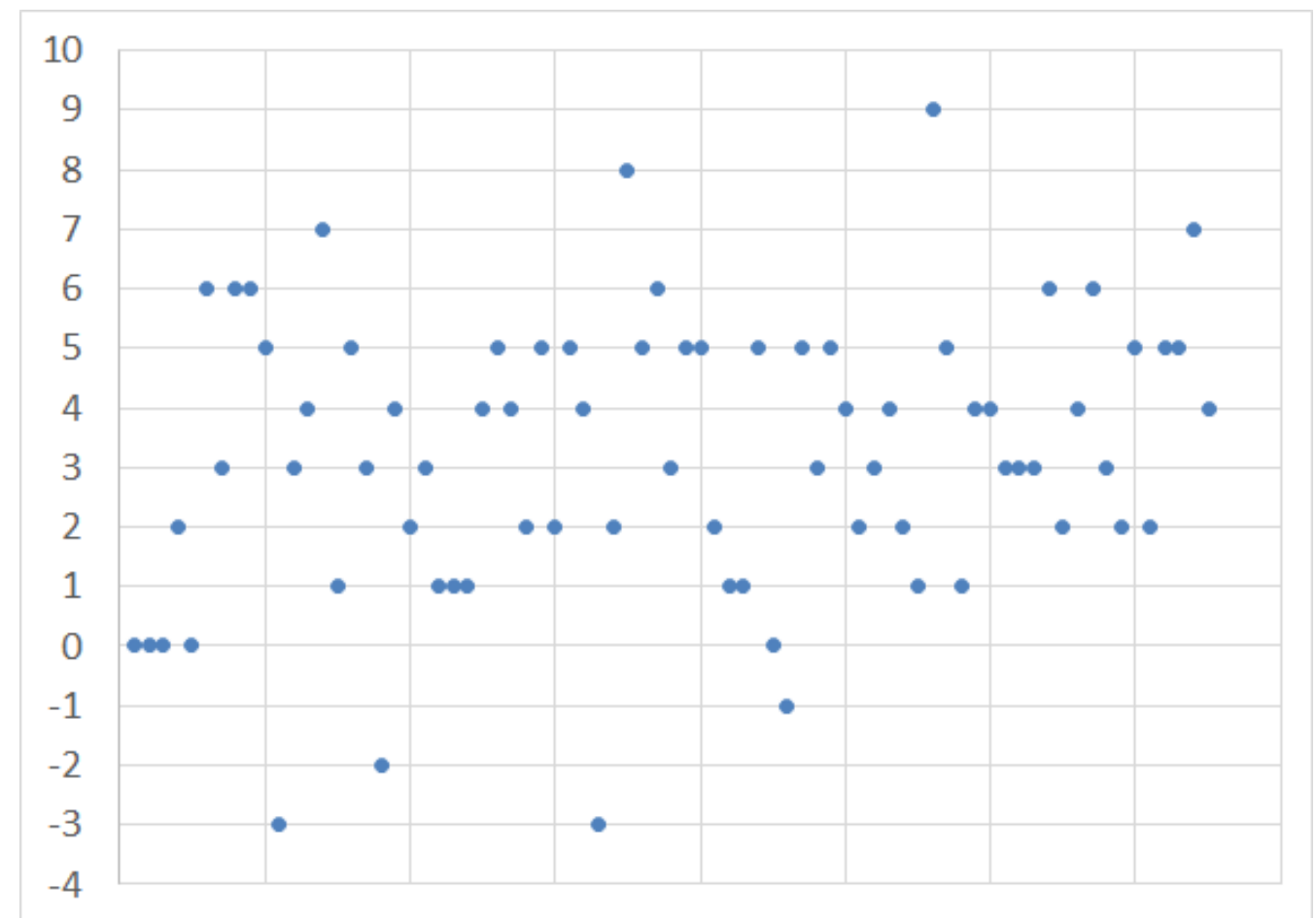

Figure 9. Scatter diagram showing per respondent difference between the number of digital components that are likely to be included in post-lockdown visits and the number of digital components that were used in pre-covid visits.

\section{"11. In your opinion, is there a future for blended (face-to-face and digital) school visits in the longer term, post-pandemic? Explain your answer."}

Nearly all participants (95\%) said that there will/may be a future for blended (face-toface and digital) school visits.
There were 75 responses to this question, $83 \%$ of which were positive, $5 \%$ negative, and $12 \%$ a cautious "maybe". In their responses, participants talked about different ways in which digital could be blended into a face-to-face school visit, and about the benefits as well as the challenges and drawbacks of blending.

Ways of blending: Pre- and/or post-visit engagement was explicitly identified as a way of blending digital with face-to-face. Also mentioned were ways in which digital could help bring the museum into the school by facilitating and/or augmenting school outreach work, for example offering live sessions (live Q\&As, talks, etc.) or recorded sessions (virtual tours, recorded films, etc.) or virtual visits or access to digital collections. The importance of physical artifacts accompanying these digital offerings, e.g. loan boxes, was also mentioned. Three respondents commented that, following the rapid familiarisation of students and teachers with online learning experiences during the lockdown, such blending will be easier if not expected by schools. The potential of blending to lead to new types of school visit experiences was identified by one participant.

Benefits of blending: Blending digital elements into school visit experiences is seen to bring several benefits. The most frequently mentioned was the potential to expand audiences by reaching schools that would otherwise not be visiting, because either their physical distance from the museum or the associated visit costs prohibit in-person visits. Similarly beneficial for the museum, is perceived to be the use of digital for school outreach in place of in-person staff visits, where benefits were mentioned related to environmental, staff time and transport costs. Support for home schooling as well as SEND groups (with pre-visit site orientation activities) and disability groups were also identified. Several 
benefits were identified related to improving the learning experience, including sustaining engagement beyond the physical visit, supporting curriculum topics, supporting small group work, increasing interactivity, aiding understanding and supporting teachers. Finally, benefits related to the pandemic context were identified including its potential to help build audience confidence for physical visits, catering for shielding children, and replacing physical visits when necessary.

Challenges and drawbacks of blending: A major drawback in blending digital elements into school visits is the danger that students miss out on physical interactions with objects and artifacts as well as the benefits of immersing into the physical and social environment of the museum. Losing out on handson activities, interactions with museum experts, opportunities to learn outside the classroom, and the danger of a diluted learning experience were mentioned. Another major drawback is the cost associated with the development of digital elements, including both budgetary and staffing issues related to capacity and digital capabilities. Perceived school expectation for digital elements to be free were mentioned, as well as the need for a viable financial model for blended visits. The danger that digital access might diminish physical visits was also mentioned. It is worth noting that no concerns or drawbacks were raised by those participants who had identified pre- and post-visit engagement as suitable ways of blending digital elements into school visits, presumably because they imagined the addition of digital elements to mean expansion of the visit experience rather than replacement of parts of the physical experience.

This open-ended question did not ask participants explicitly to comment on ways of blending, benefits and drawbacks, therefore a quantitative analysis of responses is not appropriate. Nevertheless, it is worth noting that there were clear 'winners' in the three categories, with pre- and post-visit engagement mentioned most frequently as a way of blending digital elements, the expansion of the museum's reach to school audiences beyond its usual 'catchment' area the most frequently

The most favoured way of blending digital components into school visits was through preand post-visit engagement. The most frequently identified benefit was the expansion of the museum's reach beyond its usual catchment area. The most mentioned drawbacks were development costs and the loss of physical interactions and engagement. mentioned benefit, and the loss of physical access and associated costs the most frequently mentioned drawbacks. 


\section{Discussion}

The findings presented above are based on data from education and related museum professionals at various levels of seniority, a large proportion of whom (over 94\%) are directly involved in the planning and/or delivery of school visits and/or other public engagement activities, and the majority of whom $(88 \%)$ continued to work during the lockdown.

Respondents agreed overwhelmingly that school visits are important or very important to their museums: as an expression of their core mission, as a significant source of income, and in playing an instrumental role in driving audience development and increasing visitor numbers.

The kinds of activities that school visits involved pre-covid, paint a picture of experiences that were interactive, hands-on, explorative. While more passive activities like gallery tours, lectures and demonstrations were also used pre-covid, hands-on activities, trails and teacher-led student investigations were far more common.

Digital activities were already a part of school visits pre-covid for $40 \%$ of museums, and many more museums were including digital components such as teacher resources, social media, online collections and virtual tours. Mobile apps, online games, live / bitesize lectures and home activities were also present pre-covid, though not as extensively used.

The vast majority of respondents were certain that their museum will continue to welcome schools post-lockdown, and the majority of museums seem to have kept in contact with schools and/or teachers during lockdown - via email, newsletters, social media, and to a lesser extent through website updates and even phone calls. Given how important school visits are to museums in so many ways, it is not surprising that museums were willing to continue supporting school learning and nurturing relationships with school communities during the lockdown. But what will post-lockdown school visits look like?

The main challenge for museums, like so many other public venues, is getting health and safety right for staff and visitors. In the case of school visits, the challenge is amplified by uncertainty over what social distancing rules and regulations will be in place next autumn, what hygiene procedures will be needed to keep staff and students safe, and what new field trip policies are likely to be adopted by schools next academic year. The puzzle of the day, particularly for smaller sites, seems to be how to implement social distancing without compromising footfall to an extent that makes schools services financially unviable. The pressures are manifold: ensure that all students in a school group get the same quality of service, while taught in smaller groups and making use of limited spaces, without compromising too much the number of school groups that can be served, and without making the visit unaffordable for schools or the museum.

The survey data suggests three main approaches to responding to these challenges. The first is to 'covidproof' on-site visits through a combination of measures, including: one-way routes through the site, use of outdoors spaces, exclusive site access to school groups, timetabling of smaller group sessions, allowing time to sanitise objects and resources between sessions, making PPE available to staff, ensuring closer supervision of student groups, introducing Bring Your Own Device and/or Bring Your Own (craft) Kit policies, closely managing (if not eliminating) activities that require physical interactions, and ensuring that shared facilities such as restrooms and lunch areas are used safely. As mentioned above, the exact shape of these measures will depend on what rules and regulations are in place in the autumn; furthermore, the unpredictability of the pandemic and how it will play out next winter is likely 
to require that these measures be flexible enough to adjust to potential variances in rules and regulations in different regions at different times.

The second approach is to take the museum into the classroom through outreach activity. For some museums this will mean stepping up their outreach offer; for others it will mean introducing outreach for the first time. There are different ideas as to how to approach outreach, including how to replicate elements of the physicality of the visit and the social interactions with museum experts that are at the heart of school visits. Social distancing and sanitation are important in outreach too (e.g. quarantining / sanitising loan boxes and handling objects), however, the measures taken are easier to adapt to individual school policies and practices.

The third approach is to step up the use of digital tools and resources to deliver all or part of the school experience remotely. The inclusion of digital activities in post-lockdown visits is considered by nearly all the institutions represented in the survey; this would be c. $60 \%$ increase compared to pre-covid 19 use. Post-lockdown school offers are likely to see increased use of online collections and resources, digital tours, live sessions and virtual events, home activities, and social media; and to a lesser extent, online games and mobile apps.

Despite the increased appetite for digital activities, these are not seen as replacement of other activities - certainly not in the longer term. In fact, many respondents emphasised the benefits of being immersed in the environment of the museum and experiencing its contents first-hand, and how the introduction of digital activities may compromise the physical experience and the students' interactions with the space, the objects, and the museum's authentic environment. The following quote captures the essence of these views:

"The great thing about museums is seeing something real, not abstracted, to value that something has survived this long, that it's not just digital or part of a game. It's about interacting, having someone explain, enthuse them and share being together, learning together and body language. Having someone care enough to share it with you and teach you about it. People have been missing that personal contact during lockdown and you can't offer it digitally."

Another drawback to integrating digital activities is the associated development costs, particularly in the context of reduced budgets post-lockdown. While digital can enable the delivery of services like school visits that may be impossible to deliver otherwise, some fear that expectations for the digital elements of a museum offer to be free of charge will further impede the generation of income to boost the development of digital activities. Changing such attitudes may require additional effort.

The potential of digital activities to engage school groups in pre- and post-visit scenarios and thus engage them in deeper educational experiences (and in the shorter term of the covid19 context, to compensate for potentially shorter interactive sessions) is well recognised; as is the potential to serve remote and hard to reach audiences, and to enhance outreach activity (e.g. to by complementing loan boxes with digital resources and live online sessions). 


\section{Conclusion}

Amidst the disruption that covid19 inflicted on the social lives of our museum and school communities, digital media and technologies offered a social lifeline. Our findings suggest that this is likely to continue post-lockdown, while our communities build the tools and the confidence to resume activity in the 'real' world. In fact, the survey responses suggest that a period of intensification of the integration of digital activities within school visits may be imminent; a period that presents unique opportunities to explore how critical inquiry and other museum pedagogies can guide the planning of flexible, blended school visits that combine face-to-face and online activities. In this, the museum learning sector will need support and coordinated efforts. 


\section{Appendix A: Survey questions}

\section{School visits post-lockdown}

\section{Page 1: Welcome}

\section{Introduction}

We are researchers based at the School of Museum Studies, University of Leicester. As part of the Science-MINQ project we are developing Rapid Inquiry, a pedagogical approach for framing young people's interactions during school visits to science centres.

In the context of the COVID-19 pandemic and the disruption that the imposed lockdowns have created for schools and museums alike, we are exploring alternative approaches to school visits to museums in the immediate future and beyond. Specifically, how learning inquiries and other pedagogical approaches can be pursued through blended online and face-to-face activities post-lockdown and post-covid19.

\section{About your participation}

This survey is for museum educators and other museum professionals who are involved in the planning and/or delivery of school visits. It focuses on understanding the likely disruptions, challenges and changes in school visits as a result of covid19.

The survey takes approximately 20 minutes to complete. You will NOT be asked for any personal details (such as your name or the name of your museum). If you wish to receive information about the next stage of this project you will be asked to disclose your email address so that we can contact you. We will not use your email address for any other purposes, now or in the future.

Your responses will be used to inform the planning of future research in this area.

\section{Protecting your confidentiality}

Any information that you provide will be anonymous and will be treated as confidential. Data collection and processing will comply with the General Data Protection Requirements (GDPR). Questionnaire data will be encrypted and kept securely on University of Leicester file systems for five years after the publication of findings, then will be permanently deleted. 
If you have any questions about the ethical conduct of this research, please contact the Leicester Museum Studies Research Ethics Officer, Dr Dave Unwin (dmu1@le.ac.uk).

How to contact us:

If you would like any further information before taking part, please contact:

Dr Stamatina Anastopoulou, EU Marie Sklodowska-Curie Research Fellow, University of Leicester (email: stamatina.anastopoulou@le.ac.uk)

Dr Giasemi Vavoula, Associate Professor in Museum Studies, University of Leicester (email: g.vavoula@le.ac.uk).

School of Museum Studies, University of Leicester, Leicester LE1 7RA, UK

By pressing the Next button you agree that you have read and understood the information above and you agree that your anonymised contributions will be used for the stated purposes. 


\section{Page 2: Your museum's pre-covid19 school visit offer}

In this section you are asked questions about your museum's pre-covid19 school visit offer.

Note: Think of "your museum" as the museum that you worked with/for most recently.

In your opinion, how important are school visits to your museum?

Please don't select more than 1 answer(s) per row.

\begin{tabular}{l|c|c|c|c|c|} 
& $\begin{array}{c}\text { Very } \\
\text { Important }\end{array}$ & Important & $\begin{array}{c}\text { Moderately } \\
\text { Important }\end{array}$ & $\begin{array}{c}\text { Slightly } \\
\text { Important }\end{array}$ & $\begin{array}{c}\text { Not } \\
\text { Important }\end{array}$ \\
\hline $\begin{array}{l}\text { Importance of } \\
\text { school visits }\end{array}$ & $\digamma$ & $\Gamma$ & $\Gamma$ & $\Gamma$ & $\Gamma$ \\
\hline
\end{tabular}

In your opinion, what makes school visits important for your museum?

Which of the following types of activity did your museum's pre-covid19 school visit offer include (tick all that apply):

$\Gamma$ Self-guided student investigations

$\ulcorner$ Teacher-guided student investigations

$\Gamma$ Trails

$\Gamma$ Critical thinking activities

$\ulcorner$ Hands-on activities

$\ulcorner$ Watching demonstrations or lectures

$\ulcorner$ Playing with interactive exhibits

$\ulcorner$ Gallery tours 


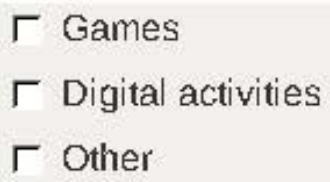

If you selected Other, please specify:

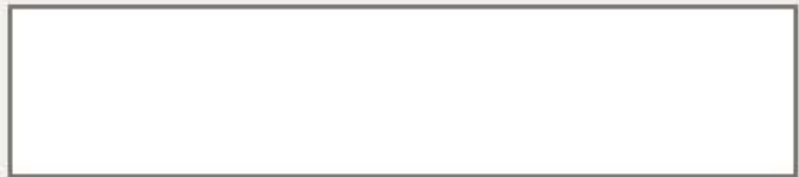

If your museum's pre-covid19 school visit offer included diggital activities, which of the following were used? Tick all that apply.

$\Gamma$ None, we do not offer digital activities

$\ulcorner$ Online collections

$\Gamma$ Social media

$\Gamma$ Virtual tours

$\ulcorner$ Mobile apps

$\ulcorner$ online games

$\ulcorner$ Teacher resources

$\ulcorner$ Home activities

$\Gamma$ Live lectures

$\ulcorner$ Bitesize talks

$\Gamma$ Other

If you selected Other, please specify: 


\section{Page 3: Your museum's post-lockdown school visit plans}

In this section you are asked questions about your museum's current thinking regarding school visits post-lockdown.

Note: Think of "your museum" as the museum that you worked with/for most recently.

To your knowledge, is your museum considering to offer a school visit service post-lockdown?
$r$ Yes
$r$ No
$r$ I am not sure

To your knowledge, has your museum been able to keep relationships with schools going during the lockdown?
$r$ Yes
$r$ No
r I am not sure

How has your museum done this?

What issues or challenges do you anticipate your museum will face in resuming its school visits service post-lockdown? 


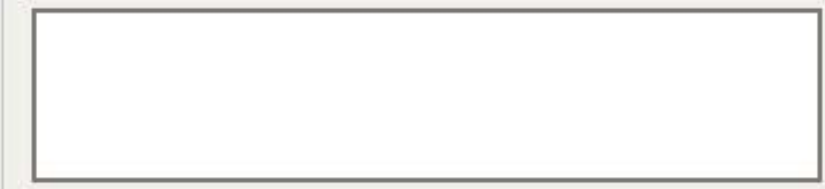

How do you expect social distancing to impact school visits to your museum?

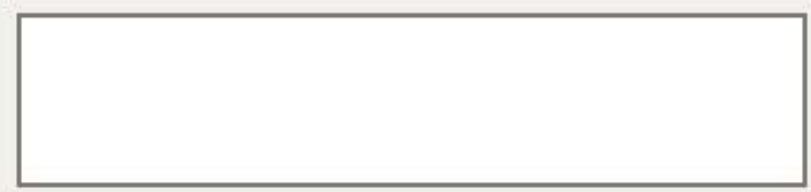

To your knowledge, are there plans to make any modifications post-lockdown to your museum's school visit offer? If yes, what modifications are being considering?

Are there any other school visit modifications that you think your museum should consider? Please explain.

How likely do you think it is that your museum's post-lockdown school visit offer will include the following types of activity?

Please dorit select more thar 1 answer(s) per row. 


\begin{tabular}{|c|c|c|c|c|c|c|}
\hline & Definitely & Probably & Possibly & $\begin{array}{c}\text { Probably } \\
\text { Not }\end{array}$ & $\begin{array}{c}\text { Definitely } \\
\text { Not }\end{array}$ & $\begin{array}{l}\text { I do not } \\
\text { know }\end{array}$ \\
\hline $\begin{array}{l}\text { Self-guided } \\
\text { student } \\
\text { investigations }\end{array}$ & $\Gamma$ & $\Gamma$ & $\Gamma$ & $\Gamma$ & $\Gamma$ & $\Gamma$ \\
\hline $\begin{array}{l}\text { Teacher-guided } \\
\text { student } \\
\text { investigations }\end{array}$ & $\Gamma$ & $\Gamma$ & $\Gamma$ & $\Gamma$ & $\Gamma$ & $\Gamma$ \\
\hline Trail & $\Gamma$ & $\Gamma$ & $\Gamma$ & $\Gamma$ & $\Gamma$ & $\Gamma$ \\
\hline $\begin{array}{l}\text { Critical thinking } \\
\text { activities }\end{array}$ & $\Gamma$ & $\Gamma$ & $\Gamma$ & $\Gamma$ & $\Gamma$ & $\Gamma$ \\
\hline $\begin{array}{l}\text { Hands-on } \\
\text { activities }\end{array}$ & $\Gamma$ & $\Gamma$ & $\Gamma$ & $\Gamma$ & $\Gamma$ & $\Gamma$ \\
\hline $\begin{array}{l}\text { Watching } \\
\text { demonstrations } \\
\text { or lectures }\end{array}$ & $\Gamma$ & $\Gamma$ & $\Gamma$ & $\Gamma$ & $\Gamma$ & $\Gamma$ \\
\hline $\begin{array}{l}\text { Playing with } \\
\text { interactive } \\
\text { exhibits }\end{array}$ & $\Gamma$ & $\Gamma$ & $\Gamma$ & $\Gamma$ & $\Gamma$ & $\Gamma$ \\
\hline Gallery tours & $\Gamma$ & $\Gamma$ & $\Gamma$ & $\Gamma$ & $\Gamma$ & $\Gamma$ \\
\hline Games & $\Gamma$ & $\Gamma$ & $\Gamma$ & $\Gamma$ & \ulcorner & Г \\
\hline Digital activities & $\Gamma$ & $\Gamma$ & $\Gamma$ & $\Gamma$ & $\Gamma$ & $\Gamma$ \\
\hline
\end{tabular}

Are there any other types of activity that you think are likely to be included or should be included? 


\section{Page 4: Digital activities and school visits post-lockdown}

In this section you are asked questions about the inclusion of digital activities in school visits at your museum post-lockdown.

Note: Think of "your museum" as the museum that you worked with/for most recently.

How important do you think digital activities will be in your museum's postlockdown school offer?

Please don't select more than 1 answer(s) per row.

\begin{tabular}{l|c|c|c|c|c|} 
& $\begin{array}{c}\text { Very } \\
\text { Important }\end{array}$ & Important & $\begin{array}{c}\text { Moderately } \\
\text { Important }\end{array}$ & $\begin{array}{c}\text { Slightly } \\
\text { Important }\end{array}$ & $\begin{array}{c}\text { Not } \\
\text { Important }\end{array}$ \\
\hline Digital activities & $\Gamma$ & $\Gamma$ & $\Gamma$ & $\Gamma$ & $\Gamma$ \\
\hline
\end{tabular}

Which of the following do you think are likely to be used in digital activities of your museum's post-lockdown school visits?
$\Gamma$ Online collections
$\ulcorner$ Social media
$\ulcorner$ virtual tours
$\ulcorner$ Mobile apps
$\ulcorner$ Online games
$\ulcorner$ Teacher resources
$\ulcorner$ Home activities
$\ulcorner$ Live lectures
$\ulcorner$ Bitesize talks
$\ulcorner$ Other 
If you selected Other, please specify:

In your opinion, is there a future for blended (face-to-face and digital) school visits in the longer term, post-pandemic? Explain your answer. 


\section{Page 5: About you}

In this section you are asked questions about your role in your museum.

Note: Think of "your museum" as the museum that you worked with/for most recently.

How would you describe your role in your museum?

How often does your role in your museum require you to undertake tasksiresponsibilities related to the planning and delivery of school visits or other public engagement activities (e.g. drop in workshops, lectures, etc.)?

Please dorit select more than 1 answer(s) per row.

\begin{tabular}{l|c|c|c} 
& Regularly & Occasionally & Never \\
\hline I am involved in the planning of school visits & $\Gamma$ & $\Gamma$ & $\Gamma$ \\
\hline I am involved in the delivery of school visits & $\Gamma$ & $\Gamma$ & $\Gamma$ \\
\hline $\begin{array}{l}\text { I am involved in the planning of other public } \\
\text { engagement activities }\end{array}$ & $\Gamma$ & $\Gamma$ & $\Gamma$ \\
\hline $\begin{array}{l}\text { I am involved in the delivery of other public } \\
\text { engagement activities }\end{array}$ & $\Gamma$ & $\Gamma$ & $\Gamma$ \\
\hline
\end{tabular}

What is your current employment situation? 
$r$ Working from home

$r$ Working at the museum

$r$ Furloughed

$r$ Other

If you selected Other, please specify:

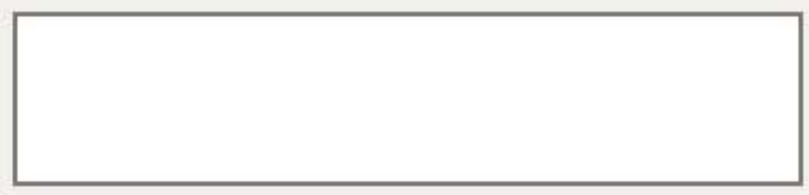

Do you have any other comments or suggestions?

We are developing a project to explore the use of inquiry learning in planning flexible, blended school visits that combine face-to-face and online activities. If you are interested to know more or want to be involved, please email us or insert your email below and we will contact you. 


\section{Page 6: Final page}

Thank you for taking the time to complete this survey. We truly value the information that you have provided. Your responses will contribute to our better understanding of the issues and considerations that museums are currently grappling with in relation to school visits in the post-lockdown world.

Many thanks,

Stamatina and Giasemi

The Science-MINQ Project Team

Dr Stamatina Anastopoulou (stamatina.anastopoulou@le.ac.uk)

Dr Giasemi Vavoula (g.vavoula@le.ac.uk).

School of Museum Studies,

University of Leicester,

19 University Road,

Leicester, LE1 7RF 


\section{For more information}

Dr Giasemi Vavoula and

Dr Stamatina Anastopoulou

School of Museum Studies

University of Leicester

19 University Road

Leicester, LE1 7RA, UK

t: +44 (0) 1162523966

e: g.vavoula@le.ac.uk,

stamatina.anastopoulou@le.ac.uk 